\title{
Prolonged carriage of Clostridium difficile in Hirschsprung's disease
}

\author{
S P Hardy, R Bayston, L Spitz
}

\begin{abstract}
The role of Clostridium difficile in the aetiology of diarrhoea in children with Hirschsprung's disease was investigated in a prospective longitudinal study. In 64 children with Hirschsprung's disease no significant difference was found in the isolation rate of $C$ difficile in patients with diarrhoea $(32 \%)$ and without diarrhoea $(26 \%)$.
\end{abstract}

Comparable isolation rates were found in 47 control children with and without diarrhoea (27\% and $16 \%$ respectively). The number of strains producing toxin $B$ was similar in the four groups of children.

In contrast to the disappearance of $C$ difficile by 12 months of age in the control groups of children, $C$ difficile could be repeatedly isolated from a proportion of children with Hirschsprung's disease over 12 months of age. These findings help to reconcile the existing contradictory reports on the incidence of $C$ difficile in Hirschsprung's disease associated enterocolitis.

(Arch Dis Child 1993; 69: 221-224)

Diarrhoea, varying in severity from loose stools to life threatening enterocolitis, is a common complication in children with Hirschsprung's disease. ${ }^{1-5}$ The enterocolitis is associated with a significant morbidity and mortality in children.

Thomas et al reported an increased isolation rate of Clostridium difficile and production of cytopathic toxin from the stools of children with Hirschsprung's disease enterocolitis (defined as onset of loose stools) compared with children whose Hirschsprung's disease was not complicated by enterocolitis. ${ }^{67}$ Wilson-Storey et al, in contrast, found no association between $C$ difficile and enterocolitis in newly diagnosed patients with Hirschsprung's disease up to 2 years of age. ${ }^{8}$

Toxigenic $C$ difficile can be isolated from the stools of a high proportion of healthy children up to 18 months of age without any apparent disease $^{9-12}$ yet fatal pseudomembranous colitis has been described in children with Hirschsprung's disease. ${ }^{1314}$ Consequently, the significance of $C$ difficile in the aetiology of diarrhoea in children with Hirschsprung's disease remains uncertain.

We have examined the causes of diarrhoea and the isolation rate and toxigenicity of $C$ difficile in a longitudinal study of children with Hirschsprung's disease treated at the Hospitals for Sick Children, London during

the period from 1988-91.

\section{Patients and methods PATIENTS}

A total of 122 stool samples were obtained from 64 children with Hirschsprung's disease and 47 control children (children without any primary intestinal disease) admitted to hospital or seen as outpatients. Each visit was considered as a separate episode. If more than one specimen was obtained from a child during the stay in hospital it was considered as a separate episode only if obtained four weeks after the previous specimen.

The samples were categorised into four groups with the number of episodes from the number of children as follows. Group I: Hirschsprung's disease without diarrhoea; 31 episodes from 27 children. Group II: Hirschsprung's disease with diarrhoea; 44 episodes from 37 children. Group III: controls without diarrhoea; 25 episodes from 25 children. Group IV: controls with diarrhoea; 22 episodes from 22 children. Episodes of diarrhoea were considered either as sporadic (one recorded episode of loose stools lasting for less than two weeks) or chronic/recurrent (lasting over two weeks and presenting with loose stools more than twice in a year).

\section{BACTERIOLOGICAL CULTURE}

In addition to routine microbiological investigations, stool specimens were examined for the presence of $C$ difficile using cycloserine-cefoxitin-fructose agar (Oxoid-Unipath Ltd) and incubated for $\mathbf{4 8}$ hours.

\section{DIFFICILE TOXIN B TESTING}

The isolates of $C$ difficile were tested for the production of the cytotoxin toxin B using a 48 hour culture supernatant tested on human embryonic lung cells and cytopathic effect was identified by neutralisation with Clostridium sordellii antitoxin (Wellcome Ltd).

\section{EDTA-SOLUBLE PROTEIN PATTERNS}

The EDTA-soluble protein pattern of $C$ difficile was used to type the isolates. ${ }^{15}$ The EDTA-soluble antigens were prepared using the method of Poxton and Byrne ${ }^{16}$ and run on $12.5 \%$ gels using the PhastSystem. Bands were visualised using the manufacturers' silver stain method.

\section{STATISTICAL ANALYSIS}

Differences between groups were tested for using the $\chi^{2}$ test with Yates's correction. Significance was taken at $95 \%$.

\footnotetext{
Dr $S$ P Hardy, Department of Cell Biology, AFRC, CB2 4AQ.

Accepted 28 April 1993

Health, London, Paediatric Surgery S P Hardy

Academic Microbiolog

Correspondence to:
} 
Incidence of $\mathrm{C}$ difficile in children with Hirschsprung's disease and controls

\begin{tabular}{|c|c|c|c|c|c|c|c|}
\hline \multicolumn{4}{|c|}{ Hirschsprung's disease } & \multicolumn{4}{|c|}{ Controls } \\
\hline \multicolumn{2}{|c|}{$\begin{array}{l}\text { Group I } \\
\text { (no diarrhoea) }\end{array}$} & \multicolumn{2}{|c|}{$\begin{array}{l}\text { Group II } \\
\text { (with diarrhoea) }\end{array}$} & \multicolumn{2}{|c|}{$\begin{array}{l}\text { Group III } \\
\text { (no diarrhoea) }\end{array}$} & \multicolumn{2}{|c|}{$\begin{array}{l}\text { Group IV } \\
\text { (with diarrhoea) }\end{array}$} \\
\hline$C D+$ & $C D-$ & $C D+$ & $C D-$ & $C D+$ & $C D-$ & $C D+$ & $C D-$ \\
\hline $\begin{array}{l}7 \\
7 \\
3 \cdot 7 \\
2-8 \\
0\end{array}$ & $\begin{array}{l}24 \\
20 \\
29 \cdot 3 \\
<1-132\end{array}$ & $\begin{array}{l}16 \\
12 \\
40 \cdot 5 \\
<1-180 \\
7(44)\end{array}$ & $\begin{array}{l}28 \\
25 \\
50 \cdot 4 \\
<1-162\end{array}$ & $\begin{array}{l}4 \\
4 \\
3 \cdot 3 \\
1-7 \\
0\end{array}$ & $\begin{array}{l}21 \\
21 \\
27 \cdot 3 \\
<1-156\end{array}$ & $\begin{array}{l}6 \\
6 \\
7 \cdot 7 \\
4-12 \\
0\end{array}$ & $\begin{array}{l}16 \\
16 \\
26 \cdot 2 \\
2-156\end{array}$ \\
\hline $4(57)$ & & $8(50)$ & & $2(50)$ & & $2(33)$ & \\
\hline
\end{tabular}

No of episodes

No of patients

Mean age (months)

Range

No $(\%)>18$ months $^{\star}$

No $(\%)$ producing

toxin $\mathrm{B} \uparrow$

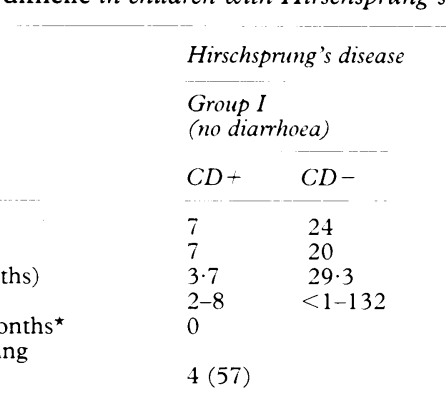

$\mathrm{CD}+: C$ difficile isolated; $\mathrm{CD}-: C$ difficile not isolated.

* Number of episodes in children over 18 months old. + Production of toxin B by strains of $C$ difficile.

\section{Results}

ISOLATION RATE OF C DIFFICILE

The isolation rate of $C$ difficile from the four groups of children is given in the table. No significant difference was found between the four groups of children when analysed either by the number of episodes (group I: 23\%; group II: $36 \%$; group III: $16 \%$ group IV: $27 \%$; $\mathrm{p}>0.05$ ) or by the number of children (group

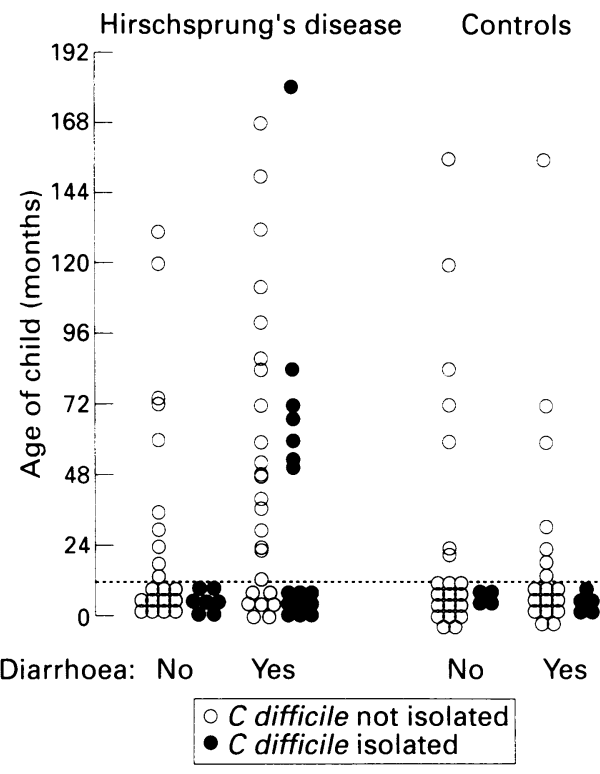

Figure 1 Age range of children from whom stool samples were cultured. Note the prolonged carriage of $\mathrm{C}$ difficile in children with Hirschsprung's disease with diarrhoea.

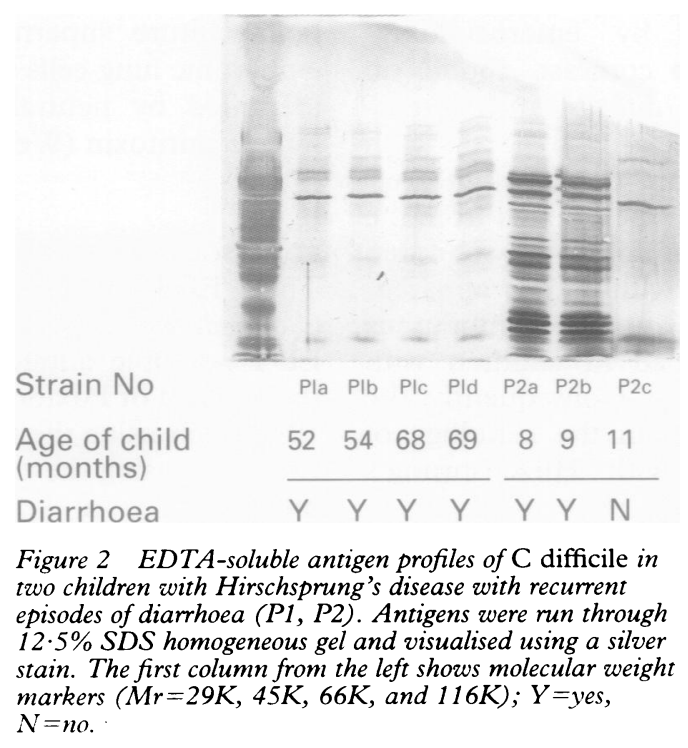

I: $26 \%$; group II: $32 \%$; group III: $16 \%$; group IV: $27 \% ; \mathrm{p}>0 \cdot 2$ ).

Of the children with Hirschsprung's disease and diarrhoea, the isolation rate of $C$ difficile was not significantly different between those with sporadic diarrhoea (six out of 18 children: $33 \%$ ) and those with chronic or recurrent diarrhoea (six out of 19 children: $32 \% ; \mathrm{p}>0 \cdot 1)$.

In the children with sporadic diarrhoea microbial enteropathogens were identified in 13 of the 18 children (adenovirus four, rotavirus one, small round structured virus one, enteropathogenic Escherichia coli two, enterotoxigenic $E$ coli one, Campylobacter jejuni one, Aeromonas hydrophila two, and cysts of Cryptosporidium $\mathrm{sp}$ one). Other than $C$ difficile and one adenovirus (see below), no enteropathogens were identified in the children with recurrent/chronic diarrhoea.

PRODUCTION OF TOXIN B

There was no significant difference in the proportion of strains of $C$ difficile that produced toxin $\mathrm{B}$ between the four groups of children (table).

AGE RELATED CARRIAGE OF C DIFFICILE

The age distribution of the isolation rates of $C$ difficile was examined. $C$ difficile was isolated with similar frequency in all four groups of children up to 12 months of age, whereas in children over 12 months $C$ difficile could be isolated only in children from group II. The pattern of isolation is shown in fig 1 and the details of the age distribution are given in the table.

EDTA-SOLUBLE ANTIGEN TYPING

Repeated isolation of $C$ difficile was seen in two children with Hirschsprung's disease in group II who had recurrent episodes of diarrhoea. One child (P1) had undergone total colonic resection for long segment Hirschsprung's disease. Stool samples were obtained during four separate episodes of diarrhoea over a two year period from which $C$ difficile was isolated in each case. The strains were all non-toxigenic and had identical EDTA-soluble antigen profiles on analysis with sodium dodecylsulphatepolyacrylamide gel electrophoresis (SDSPAGE) (fig 2). No other enteric pathogens were isolated. 
The second child (P2) had four episodes of diarrhoea in which stool samples were collected. $C$ difficile was isolated during two of these episodes. Both strains were toxigenic and had identical EDTA antigen profiles (fig 2). In the other two samples adenovirus was seen on electron microscopic analysis in one and no enteric pathogen was identified in the other. A toxigenic strain of $C$ difficile was also isolated when the child was not suffering from diarrhoea (P2c; fig 2). In both children treatment with oral vancomycin resulted in the disappearance of $C$ difficile from the faeces within two weeks.

\section{Discussion}

A significant incidence of enterocolitis both before and after pullthrough surgery has been reported in several large series. ${ }^{21718}$ The differentiation between enterocolitis and gastroenteritis is difficult but important if enterocolitis is to be promptly treated.

Diarrhoea of short duration (lasting less than one week) resembling gastroenteritis was associated with microbial enteropathogens whereas chronic/recurrent diarrhoea was mostly not. Although microbial enteropathogens have not been found in most studies on Hirschsprung's disease associated enterocolitis, rotavirus ${ }^{8}$ and enteropathogenic $E$ coli $^{19}$ have been described in more recent studies. Our findings of virus identification in a high proportion of children with Hirschsprung's disease and diarrhoea suggest that microbial enteropathogens, particularly enteric viruses, are an important cause of diarrhoea in these children.

A high incidence of colonisation with $C$ difficile in children with Hirschsprung's disease was found but no significant difference existed between the isolation rate or toxigenicity of isolates of $C$ difficile from those children with or without diarrhoea. $C$ difficile is a common isolate from the stools of children. The isolation rate falls quickly to adult rates (approximately $3 \%$ ) after 12 months of age. ${ }^{20}$

The isolation of $C$ difficile in children over 12 months of age could explain the apparently contradictory results of the previous studies by Thomas et $a l^{67}$ and Wilson-Storey et al. ${ }^{8} \mathrm{In}$ children up to 12 months of age no difference will exist in the incidence of colonisation with $C$ difficile, whereas prolonged carriage in children with Hirschsprung's disease and diarrhoea will occur after 12 months of age and thereby create an association between diarrhoea and $C$ difficile.

The prolonged carriage of $C$ difficile seen in the older children with Hirschsprung's disease and diarrhoea might result from repeated antibiotic treatment during hospital admissions. The staged course of treatment of Hirschsprung's disease usually involves three admissions for surgery with appropriate antibiotic prophylaxis. Previous studies have indicated that repeated exposure to antibiotics permits colonisation with $C$ difficile in adults with inflammatory bowel disease ${ }^{9}$ and children with cystic fibrosis. ${ }^{21}$ However, no evidence for this phenomenon was found in a study of children up to 18 months old by Tullus et al. ${ }^{22}$

The two cases of repeated isolation of $C$ difficile illustrate the difficulty in ascribing a pathogenic role to this organism in children over 12 months of age. The first child (P1) had repeated isolation of $C$ difficile, which had identical EDTA-soluble antigen profiles suggesting that the child was colonised with the same strain. However, all four isolates were nontoxigenic.

In the second child (P2) all the $C$ difficile isolates were toxigenic and disappeared after vancomycin treatment suggesting a causal role in the diarrhoea. However, toxigenic $C$ difficile was isolated again when the child was asymptomatic (P2c; fig 2) and further episodes of diarrhoea responded to vancomycin despite the fact that $C$ difficile was not isolated.

The significance of $C$ difficile in this age group remains difficult to interpret but treatment with vancomycin may still be appropriate.

In summary, although the overall incidence and toxigenicity of $C$ difficile was similar in children with Hirschsprung's disease and diarrhoea, an association was found between prolonged intestinal carriage of $C$ difficile in children with Hirschsprung's disease and diarrhoea over 12 months of age, which was not seen in children with Hirschsprung's disease without diarrhoea or in control children. Although a causal role cannot be established, these findings help to reconcile previous contradictory studies on the association of toxigenic $C$ difficile with children with Hirschsprung's disease.

This study was supported by a project grant from Action Research.

1 Lister J, Tam PKH. Hirschsprung's disease. In: Lister J, Irving IM, eds. Neonatal surgery. London: Butterworth, 1990: 523-46.

2 Nixon HH. Hirschsprung's disease: progress in management and diagnosis. World f Surg 1985; 9: 189-202.

3 Sherman JO, Snyder ME, Weitzman JJ, Jona JZ, Gillis DA, Swenson O. A 40 year multinational retrospective study of 880 Swenson procedures. F Pediatr Surg 1989; 24: 833-8.

4 Tariq GM, Brereton RJ, Wright VM. Complications of endorectal pull-through for Hirschsprung's disease. f Pediatr Surg 1991; 26: 1202-6.

5 Levy M, Reynolds $M$. Morbidity associated with total colon Hirschsprung's disease. $\mathcal{F}$ Pediatr Surg 1992; 27: 264-7.

6 Thomas DFM, Fernie DS, Malone M, Bayston R, Spitz L. Association between Clostridium difficile and enterocolitis in Hirschsprung's disease. Lancet 1982; i: 78-9.

7 Thomas DFM, Fernie DS, Bayston R, Spitz L, Nixon HH. Enterocolitis in Hirschsprung's disease: a controlled study of the aetiologic role of Clostridium difficile. $\mathcal{F}$ Pediatr Surg 1986; 21: 22-5.

8 Wilson-Storey D, Scobie WG, McGenity KG. Microbiological studies of the enterocolitis of Hirschsprung's disease. Arch Dis Child 1990; 65: 1338-9.

9 George RH. The carrier state: Clostridium difficile. f Antimicrob Chemother 1986; 18 suppl A: 47-58.

10 Phua TJ, Rogers TT, Pallett AP. Prospective study of Clostridium difficile colonisation and para-cresol detection in the stools of babies on a special care unit. Fournal of Hygiene (Cambridge) 1984; 93: 17-25.

11 Viscidi R, Willey S, Bartlett JG. Isolation rates and toxigenic potential of Clostridium difficile isolates from various patient populations. Gastroenterology 1981; 81: 5-9.

12 Richardson SA, Alcock PA, Gray J. Clostridium difficile and its toxin in healthy neonates. $B M F 1983 ; 287: 878$.

13 Brearly S, Armstrong GR, Nairn R, et al. Pseudomembranous colitis: a lethal complication of Hirschsprung's disease unrelated
J Pediatr Surg 1987; 22: 257-9.

14 Price EH, Borriello SP, Ward H, Brereton R, Risdon RA, Price EH, Borriello SP, Ward $\mathrm{H}$, Brereton R, Risdon RA,
Tabaqchali S. Clostridium difficile and severe enterocolitis in three infants. In: Borriello SP, ed. Clinical and molecular aspects of anaerobes. Petersfield: Wrightson Biomedical Publishing, 1990: 75-9.

15 Wexler H, Mulligan ME, Finegold SM. Polyacrylamide gel electrophoresis patterns produced by Clostridium difficile. Rev Infect Dis 1984; 6: S229-34. 
16 Poxton IR, Byrne MD. Immunological analysis of the EDTA-soluble antigens of Clostridium difficile and EDTA-soluble antigens of Clostridium diffic
related species. $f$ Gen Microbiol 1981; 122: 41-6.

17 Kleinhaus S, Boley SJ, Sheran M, Sieber WK. Hirschsprung's disease: a survey of the members of the surgical section of the American Academy of Pediatrics. f Pediatr Surg 1979; 14: 588-97.

18 Ikeda K, Goto S. Diagnosis and treatment of Hirschsprung's disease in Japan. Ann Surg 1984; 199: 400-6.

19 Teitelbaum DH, Caniano DA, Qualman SJ. The pathophysiology of Hirschsprung's-associated enterocolitis: importance of histologic correlates. F Pediatr Surg 1989; 24: 1271-7.

20 Stark PL Lee A, Parsonage BD. Colonisation of the large bowel by Clostridium difficile in healthy infants: quantitative study. Infect Immun 1982; 35: 895-9.

21 Peach SL, Borriello SP, Gaya H, Barclay FE, Welch AR. Asymptomatic carriage of Clostridium difficile in patients with cystic fibrosis. F Clin Pathol 1986; 39: 1013-8. 22 Tullus K, Aronsson B, Marcus S, Mollby R. Intestinal colonisation with Clostridium difficile in infants up to 18 months of age. Eur J Clin Microbiol Infect Dis 1989; 8: 390-3.

\section{Cryptosporidium}

The first case of human cryptosporidial infection was described in 1976. Cryptosporidium is a protozoan parasite with a worldwide distribution, which infects birds, fish, reptiles, and other mammals as well as people. It is recognised as a common cause of acute diarrhoea and as a cause of chronic diarrhoea in the immunocompromised. Recently workers at the Queen Elizabeth Hospital for Children in London reviewed their experience over a 6.5 year period (A D Phillips and colleagues, Gut 1992; 33: 1057-61).

Cryptosporidial oocysts are identified in the stools using a modified Ziehl-Nielsen stain and this has been done as a routine on stool specimens at the Queen Elizabeth Hospital since 1983. Between October 1983 and April 1990 cryptosporidium was identified in the stools of 123 children and the notes of 109 of these were reviewed.

Cryptosporidium identifications apparently followed an annual cycle with a peak in spring and a trough in autumn. One hundred of the 109 patients presented with diarrhoea which was usually watery and offensive and occasionally the stools contained mucus or blood. Non-diarrhoeal presenting symptoms were abdominal pain $(n=4)$, vomiting $(n=4)$, fever $(n=3)$, and nausea $(n=1)$. Fifty two $(58 \%)$ of 90 children for whom the duration of diarrhoea was known had diarrhoea lasting for 14 days or more. It lasted for three weeks or more in $\mathbf{3 5}$ and for over six months in seven. Eventual spontaneous resolution occurred in all the children. None had evidence of immunodeficiency. Chronic diarrhoea was more common in younger children and in those with mixed infections. Other pathogens detected included Giardia lamblia, aeromonas, enteropathogenic Escherichia coli, shigella, salmonella, campylobacter, rotavirus, adenovirus, calicivirus, and astrovirus.

There were 18 children who had recently been abroad, mostly on the Indian subcontinent, and 17 who led an itinerant life living usually on caravan sites. Chronic diarrhoea was more common in both of these groups.

Nine patients with chronic diarrhoea and severe failure to thrive had jejunal biopsies which showed an enteropathy in all nine. In seven the organism was seen adhering to the epithelium of the villi but not of the crypts. (In immunodeficiency it is also seen on crypt epithelium.)

The number of children who had stool specimens examined was known for only one year (1989) and in that year cryptosporidium was identified in $1.6 \%$ of cases. The authors point out that their finding that half of the children with only cryptosporidium in their stools had chronic diarrhoea (14 days or more) indicates that this may be a more important cause of chronic diarrhoea than has been realised in the past. It is uncertain whether the chronic diarrhoea is due to persisting infection or whether it is a postinfective phenomenon. 